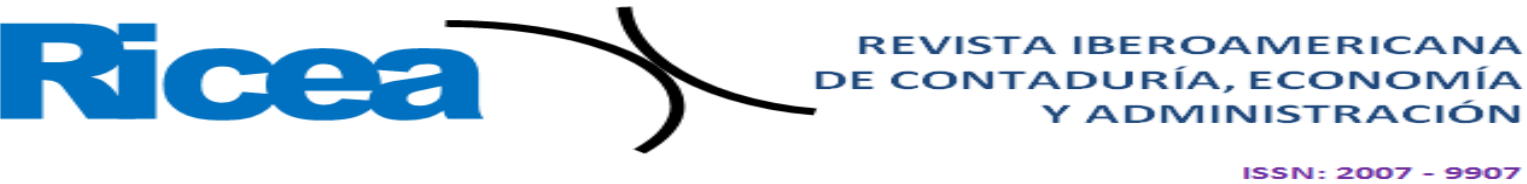

https://doi.org/10.23913/ricea.v10i19.165

Artículos Científicos

\title{
El impacto de las reformas a la ley del trabajo sobre la calidad de vida de los trabajadores
}

The Impact of the reforms to the Labour Law on The Quality of Life of Workers O impacto das reformas da legislação trabalhista na qualidade de vida dos trabalhadores

Pacheco Luis Elsa Universidad Autónoma Metropolitana, Departamento de Economía, México epluis21@gmail.com https://orcid.org/0000-0002-6986-0530

Galván Fernández María Antonina Universidad Autónoma Metropolitana, Departamento de Ingeniería y Procesos Hidráulicos, Ingeniería Hidrológica, México loralalik@gmail.com https://orcid.org/0000-0002-0288-1046

Escobedo Guerrero Gabriela Guadalupe Instituto Politécnico Nacional, Escuela Superior de Comercio y Administración, México gabrielaeg@hotmail.com https://orcid.org/0000-0002-0288-1046

\section{Resumen}

Introducción: En la década de los años setenta se consideró al neoliberalismo como la respuesta para paliar los problemas económicos mundiales, el cual pugnaba por la disolución progresiva de las fronteras económicas y políticas. Se pensaba que el libre flujo de dinero desde los países ricos en la región de Europa y Norteamérica hacia las vastas regiones pobres de África, América Latina y Oceanía era suficiente como estrategia para eliminar la pobreza y acabar con las crisis económicas recurrentes. A la par se desarrolla la globalización como un proceso de integración de todas las comunidades alrededor del mundo en los ámbitos económico, político, tecnológico, social y cultural, logrado por el desarrollo sin precedentes de los sistemas de comunicación. Este 


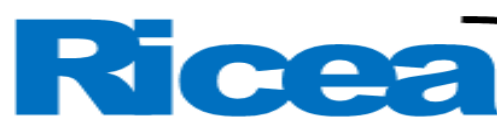

REVISTA IBEROAMERICANA DE CONTADURÍA, ECONOMÍA YADMINISTRACIÓN

ISSN $=2007-9907$

avance tecnológico favoreció el intercambio de productos y servicios, así como la conexión o movimiento de personas, y facilitó las inversiones y transacciones financieras entre mercados distantes o emergentes, acciones que antiguamente resultaban muy difíciles, altamente costosas o inviables.

La combinación de ambos fenómenos ha modificado la forma en que interactúan los países, las empresas y los individuos, de modo que, en esta última parte, ha impactado directamente en el mercado laboral, que a su vez ha modificado el ámbito jurídico y político de muchas regiones del planeta. Para lograr la competitividad solicitada internacionalmente uno de los factores clave fue la aplicación de modificaciones legislativas en materia laboral. En otras palabras, fue el concepto de flexibilización del empleo la base de modificación de la antigua ley para dejar que las fuerzas del mercado definieran su calidad.

Objetivo: En este estudio se realiza un comparativo entre la Ley Federal del Trabajo vigente en México respecto a la normativa antecesora, para lo cual se tomaron en cuenta el concepto calidad de vida, así como los indicadores propuestos por diferentes entidades internacionales.

Método: Se analizaron los indicadores mencionados bajo un sistema binario de calificación para realizar el acumulado (indicador acumulativo), elemento de comparación. La innovación de esta tarea fue la calificación de cada artículo de la ley en función de los conceptos calidad de vida y bienestar tipificados por las entidades internacionales. Esta propuesta de evaluación de las condiciones laborales de los trabajadores en México se considera más objetiva al abordar el bienestar material, los elementos de seguridad social y de realización personal.

Resultados y conclusiones: Se identifica una pérdida de elementos relacionados con la seguridad alimentaria, acceso a salud y educación, así como un retroceso en materia de seguridad laboral según los indicadores internacionales, lo que genera una precariedad laboral. Esto, en términos de desarrollo, constituye un retroceso en cuanto a las características del concepto bienestar.

Palabras clave: bienestar, competitividad, flexibilización, globalización, neoliberalismo. 


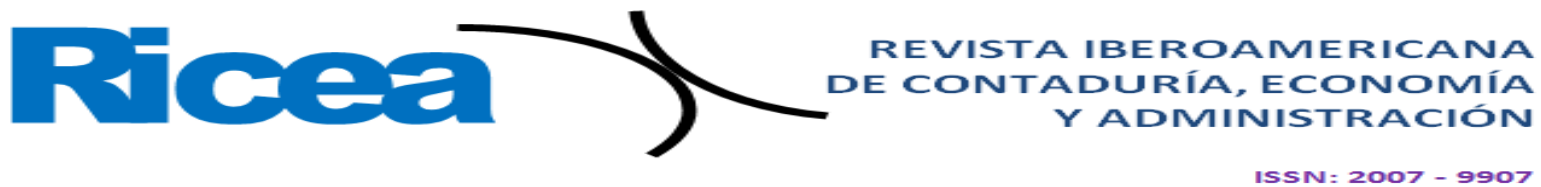

\section{Abstract}

Introduction: In the decade of the 70 's, neoliberalism was considered the answer to alleviate world economic problems, which fought for the progressive dissolution of economic and political borders. The free flow of money from rich countries in the Europe and North America region to the vast poor regions of Africa, Latin America and Oceania was thought to be sufficient as a strategy to eliminate poverty and end recurring economic crises. At the same time, globalization is developing as a process of integration of all communities around the world in the economic, political, technological, social and cultural spheres, achieved by the unprecedented development of communication systems. This technological advance favored the exchange of products and services, the connection or movement of people, also facilitated investments and financial transactions between distant or emerging markets, actions that were previously very difficult, highly expensive or unviable.

The combination of both phenomena has modified the way in which countries, companies and individuals interact in such a way that, in this last part, it has had a direct impact on the labor market, which in turn has modified the legal and political environment of many regions of the planet. To achieve the competitiveness requested internationally, one of the key factors was the legislative changes in labor matters. The concept of flexible employment is the basis for modifying the old law, to let market forces define its quality.

Objective: In this study, a comparison is made between the current Federal Labor Law, with respect to the predecessor regulations, taking as the basis of comparison the concept of quality of life and the indicators proposed by different international entities, which are used for its evaluation.

Method: The aforementioned indicators were analyzed, under a binary rating system, to make the accumulated (cumulative indicator) and which is the element of comparison. The innovation is based on qualifying each article of the Law according to the concepts of quality of life and wellbeing typified by international entities; This proposal for the evaluation of the working conditions of workers in Mexico is considered more objective when addressing material well-being, the elements of social security and personal fulfillment.

Results and conclusions: A loss of elements related to food safety, access to health and education, setback in terms of occupational safety is identified, which in global terms is lower than international indicators, causing job insecurity, and in terms of development represents a throwback of the concept of well-being. 


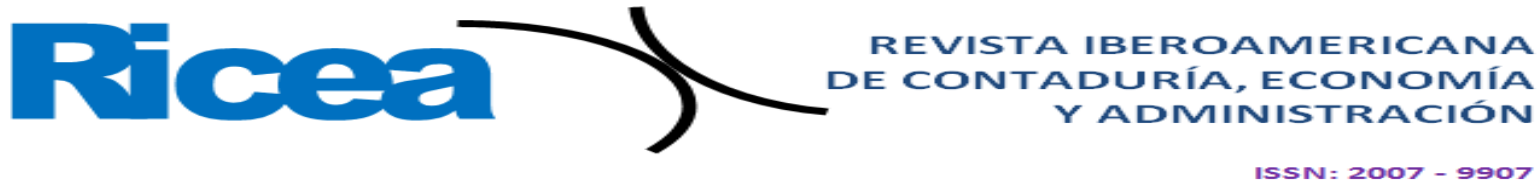

Keywords: well-being, competitiveness, flexibility, globalization, neoliberalism.

\section{Resumo}

Introdução: Nos anos setenta, o neoliberalismo era considerado a resposta para amenizar os problemas econômicos mundiais, que lutava pela dissolução progressiva das fronteiras econômicas e políticas. O fluxo livre de dinheiro dos países ricos da região da Europa e América do Norte para as vastas regiões pobres da África, América Latina e Oceania foi considerado suficiente como estratégia para eliminar a pobreza e acabar com crises econômicas recorrentes. Ao mesmo tempo, a globalização se desenvolve como um processo de integração de todas as comunidades do mundo nas esferas econômica, política, tecnológica, social e cultural, alcançado pelo desenvolvimento sem precedentes dos sistemas de comunicação. Esse avanço tecnológico favoreceu a troca de produtos e serviços, bem como a conexão ou movimentação de pessoas, e facilitou investimentos e transações financeiras entre mercados distantes ou emergentes, ações antes muito difíceis, onerosas ou inviáveis.

A combinação de ambos os fenômenos modificou a forma como países, empresas e indivíduos interagem, de forma que, na última parte, impactou diretamente no mercado de trabalho, o que por sua vez modificou o ambiente jurídico e político de muitas regiões do país. planeta. Para alcançar a competitividade exigida internacionalmente, um dos fatores-chave foi a aplicação de mudanças legislativas em matéria trabalhista. Em outras palavras, o conceito de emprego flexível foi a base para modificar a antiga lei para permitir que as forças de mercado definissem sua qualidade.

Objetivo: Neste estudo, é feita uma comparação entre a Legislação Federal do Trabalho vigente no México a respeito das normas anteriores, para as quais foi levado em consideração o conceito de qualidade de vida, bem como os indicadores propostos por diferentes entidades internacionais. Método: Os referidos indicadores foram analisados sob um sistema de classificação binária para constituir o acumulado (indicador cumulativo), elemento de comparação. A inovação desta tarefa foi a qualificação de cada artigo da lei com base nos conceitos de qualidade de vida e bem-estar tipificados por entidades internacionais. Esta proposta de avaliação das condições de trabalho dos trabalhadores no México é considerada mais objetiva quando se trata de bem-estar material, elementos de seguridade social e realização pessoal.

Resultados e conclusões: Identifica-se uma perda de elementos relacionados com a segurança alimentar, o acesso à saúde e educação, bem como um retrocesso em termos de segurança do 


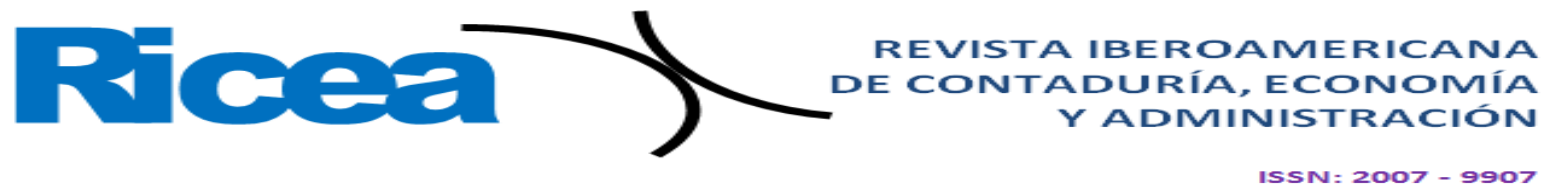

trabalho segundo indicadores internacionais, o que gera insegurança no emprego. Isso, em termos de desenvolvimento, constitui um retrocesso em termos das características do conceito de bemestar.

Palavras-chave: bem-estar, competitividade, flexibilidade, globalização, neoliberalismo.

Fecha Recepción: Julio $2020 \quad$ Fecha Aceptación: Diciembre 2020

\section{Introducción}

El neoliberalismo es la teoría político-económica que pretendía dar respuesta a los problemas económicos del siglo pasado postulando que dichos inconvenientes eran el resultado de la sobrerregulación del Estado en los procesos productivos. En consecuencia, uno de sus principios señala que la economía es el único motor de desarrollo, por lo que todo aquello que afecta al bienestar humano debe subordinarse a las leyes de mercado. Esto significa que las relaciones entre individuos y grupos sociales deben depender únicamente de los flujos de dinero entre ellos.

Sin embargo, el actual modelo de desarrollo económico pugna por una dinámica económica siempre creciente - expresada en un producto interno bruto (PIB) en aumento-, lo que en teoría debería generar condiciones de calidad de vida a la sociedad. En este nuevo escenario, el mercado proveería las bases del desarrollo para que los individuos consigan esos servicios, aunque para ello la persona debe tener la capacidad económica individual para pagarlos, lo que solo puede lograr con un empleo.

En México, el neoliberalismo surgió en medio de las crisis económicas de los años setenta provocadas por una deuda externa impagable. El efecto visible fue la apertura de la economía a la inversión de capitales extranjeros que demandaban regulaciones laborales y tributarias a su favor (lo que llamaron flexibilidad), así como mano de obra altamente calificada (englobada en el concepto competitividad). Esto trajo como consecuencia diversas modificaciones de la legislación laboral con el propósito de hacer al país altamente atractivo para la inversión extranjera, lo que generó un impacto significativo en el mercado laboral y en el ámbito jurídico y político. Sin embargo, el resultado final de esas políticas públicas fue la creación de empresas con condiciones laborales poco reguladas, donde el valor del empleo dependía de la eficiencia económica de la empresa, la cual en su fase de alta competencia incorporaba el outsourcing, con lo que se permitía a las fuerzas del mercado definir la calidad del empleo. 


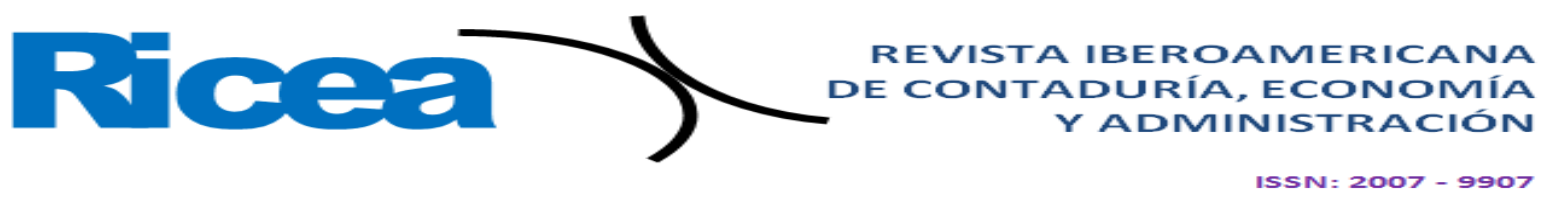

Por este motivo, en el presente estudio se realiza un comparativo entre la vigente Ley Federal del Trabajo y la normativa antecesora tomando como ejes de análisis el concepto calidad de vida y los indicadores propuestos por diferentes entidades internacionales para su evaluación. Para ello, se empleó un sistema binario de calificación de cada elemento de ambas versiones de la ley para compararlas entre sí. La innovación de este proceso radica en calificar cada artículo de la ley en función de los conceptos calidad de vida y bienestar tipificados por las entidades internacionales. Esta propuesta de evaluación de las condiciones laborales en México se considera importante porque examina el bienestar material, así como los elementos de seguridad social y de realización personal.

\section{Contexto}

El neoliberalismo retoma al liberalismo clásico del siglo XIX para insertarlo en el capitalismo actual. Surge como reacción contracultural al control del Estado como garante de justicia social, equidad y distribución de la riqueza, paradigma representativo de la década de los sesenta del siglo pasado. En esa época, el Estado actuaba como protector de los grupos sociales vulnerables frente a los intereses de otros actores económicos (p.e. las empresas).

Sin embargo, debido a los infortunios económicos del siglo XX generados por la sobrerregulación del Estado sobre los sistemas productivos, el neoliberalismo surge indicando que las funciones del referido ente debían reducirse a controlar y organizar la sociedad, ya que el mercado era capaz de suplir las otras relaciones sociales.

El neoliberalismo, por ende, afirma que el hombre es en esencia un homo economicus, por lo que si no es partícipe del mercado, simplemente no es útil para la sociedad y, en consecuencia, no existe (Foucault, 2010, 365). En otras palabras, solo cuando un individuo no asiste a relaciones comerciales y no es capaz de establecer ningún tipo de relación le corresponde al Estado incorporarlo a los circuitos económicos, pero sin intervenir en el funcionamiento de la economía, ya que esta es el único motor de desarrollo político y social. De este modo, si todos los aspectos asociados al ser humano deben estar subordinados a las leyes de mercado, entonces el libre comercio sería la base de las relaciones entre individuos y grupos sociales, y los flujos de dinero entre ellos la única forma de establecer relaciones sanas.

El neoliberalismo, por tanto, pugna por una dinámica económica creciente, lo cual —en teoría- debería generar mejores condiciones de riqueza material para los individuos y, por ende, de calidad de vida. Para lograr esta alta dinámica propone que las regulaciones al comercio y a 


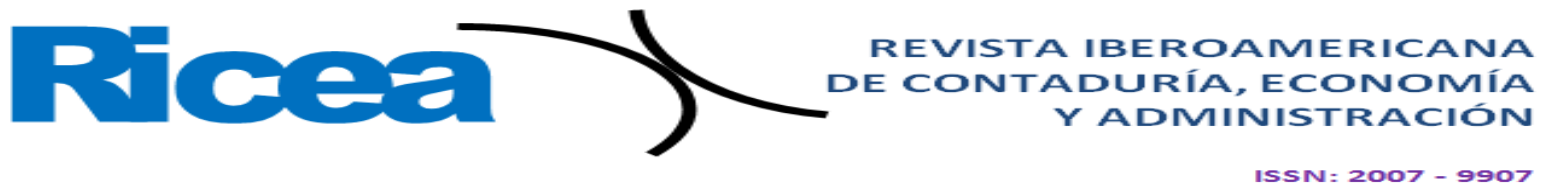

las finanzas sean muy laxas, e insta a la privatización de empresas y servicios que están en manos del gobierno argumentado que el sector privado es más eficiente para crear riqueza y ofertar servicios.

Otro elemento que promueve el neoliberalismo es la reducción del gasto social, pues considera que el mercado debe proveer las bases del desarrollo y que cada individuo debe acceder a esos servicios a través de su capacidad económica individual, lo que se sustenta en la capacidad competitiva exclusivamente.

Con estos principios, el neoliberalismo se expandió mundialmente en los años ochenta y noventa gracias a los preceptos de la globalización para formar un solo proceso de carácter económico y apoyado en la tecnología y el surgimiento de nuevos grupos sociales. El objetivo era crear un mundo donde las transferencias de dinero y mercancías fueran más rápidas, sin importar el punto geográfico o grupo social de donde provinieran los productos para ponerlos a disposición de quien contara con el dinero para comprarlos, incluidos recursos naturales y mano de obra.

En México, el neoliberalismo emergió en los años setenta debido a la disminución en los precios de petróleo, lo que impidió mantener una nómina estatal descomunal y difícil de costear. De esta forma, el Gobierno empezó a implementar una serie de acciones para "corregir" los aspectos que provocaban las crisis recurrentes, lo que supuso la privatización de un grupo importante de empresas estatales relacionadas con energía, comunicaciones y transportes. Esto exigió la reforma de leyes vinculadas a esos sectores e incluso de la propia Constitución.

Este proceso continuó con el adelgazamiento del aparato del Estado, lo que dejó sin empleo formal a un volumen importante de personas con alta capacitación, quienes quedaron a merced del mercado laboral. La sobreoferta de mano de obra capacitada impactó directamente en los salarios, así como en la pérdida de acceso a prestaciones laborales. Posteriormente, se redujo el gasto público, lo que disminuyó la calidad de los servicios de salud y de educación, así como el volumen de la población atendida. Finalmente, la economía gubernamental se abrió a la inversión extranjera de empresas multinacionales que demandaban regulaciones laborales y tributarias permisivas y trabajadores altamente capacitados. Los resultados finales fueron empresas con condiciones laborales poco o nulamente reguladas, así como un valor del empleo que dependía no de la capacidad del trabajador, sino de los parámetros de eficiencia económica que la empresa reportaba al sistema tributario. 
Figura 1. Estructura de la legitimidad empresarial



Fuente: Elaboración propia

Desde la mirada de una sociedad crítica, la falta de alguno de estos aspectos se traduce en la decadencia de la empresa. Al respecto, Freeman et al. (2010) apuntan lo siguiente: "ningún gerente podría afrontar el permitir que la diferencia entre las expectativas públicas de desarrollo y el desarrollo económico de la compañía se haga muy grande, porque entonces perdería su justificación ética" (p. 238). Entonces, la responsabilidad social empresarial, en términos generales, se puede definir como el conjunto de acciones voluntarias de la empresa que aportan al mejoramiento social, económico y ambiental de la comunidad con el objetivo de mejorar tanto la imagen corporativa que proyecta como su situación valorativa.

Los conceptos antes señalados provienen de directrices generadas por organismos internacionales como la Agencia Alemana de Cooperación Técnica [Gtz], la Organización para la Cooperación y el Desarrollo Económicos [Ocde], la Comisión Económica para América Latina y el Caribe [Cepal], entre otros. En el país, el Centro Mexicano para la Filantropía [Cemefi] define a la responsabilidad social empresarial del siguiente modo:

Una visión de negocios que integre el respeto por las personas, los valores éticos sociales, la comunidad y el medioambiente, con la gestión misma de la empresa, independientemente de los productos o servicios que esta ofrece, del sector al que pertenece, de su tamaño o nacionalidad (Cajiga, 2010, p. 2).

Contrario a esto, la noción del término bienestar no depende de cómo percibe el inversorcliente el desempeño de la empresa, sino del propio empleado y la forma en que es incorporado a los procesos de toma de decisión de la empresa. 


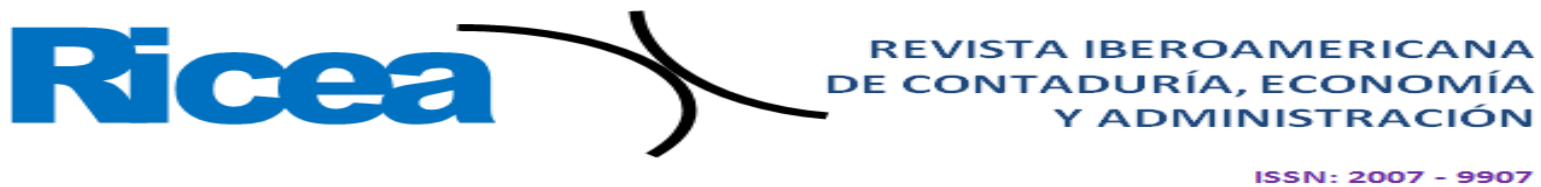

Según el Diccionario jurídico mexicano el bienestar social se define de esta forma:

La contribución de la sociedad moderna al mejoramiento de la persona a efecto de que cada vez dependa menos de su esfuerzo individual y obtenga mayores satisfactores que le permitan una vida saludable, sin graves preocupaciones y con las máximas condiciones sociales que sea posible disfrutar (Carpizo, 1982, p. 296).

En este contexto, le corresponde al Estado procurar las condiciones de desarrollo de las personas con la finalidad de que cada individuo tenga una existencia digna y segura mediante la aportación de servicios públicos que hagan agradable, atractiva e higiénica la relación con los demás para lograr una convivencia social pacífica.

\section{Desarrollo humano}

Estos conceptos han sido trasladados al ámbito laboral, donde se han convertido en un derecho fundamental e inalienable: "El otorgamiento de un salario remunerador que baste para que el trabajador pueda cubrir sus propias necesidades y las de su familia” (Carpizo, 1982, 296). Le corresponde a la empresa otorgar ese salario remunerador que le permita al trabajador a) lograr la satisfacción de sus necesidades básicas, b) procurar un ambiente laboral sano para que c) pueda alcanzar su desarrollo humano.

Esto significa que el trabajador debe contar con un ingreso económico suficiente, un ambiente laboral donde se le permita desenvolverse, se sienta aceptado y valorado, que desarrolle sus habilidades y genere un sentido de pertenencia y convivencia. Cuando la empresa es capaz de otorgar estas condiciones, se establece un círculo virtuoso que deriva en un mapa de desarrollo humano (Tabla 1).

Tabla 1. Mapa de desarrollo

\begin{tabular}{|c|c|}
\hline $\begin{array}{c}\text { Calidad de vida }=\text { Calidad de las condiciones } \\
\text { objetivas de vida }\end{array}$ & $\begin{array}{c}\text { Bienestar = Satisfacción del individuo con sus } \\
\text { condiciones de vida }\end{array}$ \\
\hline $\begin{array}{c}\text { Calidad de vida }+ \text { Satisfacción con las } \\
\text { condiciones de vida = Satisfacción personal }\end{array}$ & $\begin{array}{c}\text { Calidad de vida + Satisfacción con las } \\
\text { condiciones de vida + Satisfacción personal = } \\
\text { Valores personales }\end{array}$ \\
\hline
\end{tabular}

Fuente: Galván y Guadarrama (2017, p. 82).

En la tabla anterior, de izquierda a derecha y de arriba abajo, el campo 1 compete al individuo; el campo 2 es el desempeño del individuo en su trabajo; el campo 3 es el individuo, su trabajo y su comunidad inmediata, y el campo 4 es la suma de los tres anteriores más las 


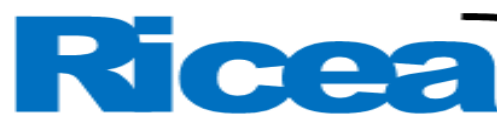

REVISTA IBEROAMERICANA DE CONTADURÍA, ECONOMÍA YADMINISTRACIÓN

$1 S S N=2007-9907$

condiciones globales de la sociedad, que generan valores positivos cuando todas son positivas. Por lo tanto, el objetivo que debiera buscar la empresa es procurar el desarrollo humano a través sus políticas empresariales para incidir en el campo 2.

\section{Calidad de vida}

De acuerdo con el Instituto Nacional de Estadística y Geografía [Inegi] (2000), "los elementos que condicionan la calidad de vida son atención a la salud, alimentación, educación, vivienda y empleo. La combinación de estos factores permite conocer las condiciones de bienestar de la población” (p. 11).

Cada factor a su vez se compone de elementos individuales de medición; por ejemplo, la salud es la base del rendimiento de las personas en lo social y lo económico, de tal forma que condiciona la eficiencia laboral. La alimentación es la base de la salud y, por tanto, la primera que se tiene que satisfacer para mantener una buena salud y una buena eficiencia laboral. En el caso de la educación, los elementos base de medición son tasa de analfabetismo, número de años de educación formalizada y grado de capacitación para el trabajo. Esto porque dicha capacitación es indispensable para el desarrollo tecnológico. La vivienda se mide como la existencia suficiente de unidades habitacionales por familia, así como de los elementos de calidad de vida que debe cubrir la vivienda: privacidad, saneamiento y seguridad. Finalmente, el empleo se refiere a la evaluación de cómo y bajo qué actividades el individuo logra tener los recursos que determinan su nivel de bienestar. Todos estos elementos, denominados dimensiones producen los indicadores de calidad de vida y, en segundo nivel, de bienestar de la población.

\section{Metodología}

Las condiciones económicas, sociales y materiales de una empresa son resultado de sus acciones en la búsqueda de crecimiento económico. Cuando el Gobierno permite que las fuerzas del mercado sean las únicas que determinen las relaciones empresa-sociedad, se obtienen resultados tanto positivos como negativos. Una empresa debe considerar no solo el efecto de las mencionadas acciones sobre su imagen y desempeño económico, sino también las relaciones que

establece con sus empleados y el medio ambiente, pues la forma en que la sociedad percibe su actuar determinará la aceptación de su labor y garantizará la subordinación necesaria para lograr sus objetivos corporativos. 


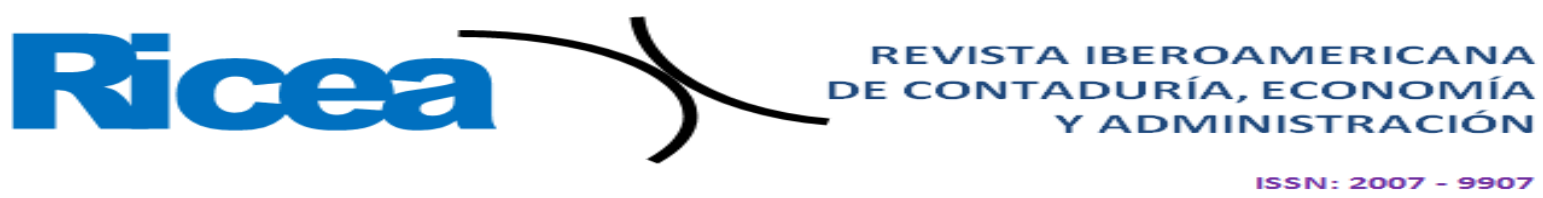

Los cambios hechos a la legislación laboral en México pretenden garantizar la competitividad de las empresas a través de la flexibilización laboral. Sin embargo, este proceso es considerado hostil por el empleado, y ha generado asimetrías en cuanto a ingresos y obligaciones, lo que ha desembocado en confrontaciones entre el trabajador y su empleador. La pregunta, por tanto, es si dichas modificaciones contienen elementos que garanticen el bienestar de los trabajadores, expresado como calidad de vida.

Para hallar una respuesta, primeramente, se construyó la base de referencia (matriz de referencia) a partir de los indicadores que los diferentes organismos internacionales proponen para determinar un trabajo decente; posteriormente, se realizaron dos matrices más: se tomó la ley citada en su versión actual (matriz a evaluar) y su antecedente (matriz de comparación), y por cada artículo se dio una valoración binaria ( 0 o 1) para crear un mapa que refleja en cada caso si aporta elementos a la calidad de vida y bienestar (de acuerdo con las definiciones de Maslow). De esta forma se procuró determinar qué nivel de necesidades se estaban cubriendo. Luego se compararon ambos mapas con la matriz de referencia para determinar si cumplían con los postulados de un trabajo decente o si existen vacíos.

\section{Resultados}

La legitimación laboral tiene su base jurídica en la Constitución Política Mexicana de 1917. En diciembre de 1916, Venustiano Carranza abre el debate en las sesiones para reformar la Constitución de 1857 cuando declara ante el Congreso Constituyente lo siguiente:

Es objeto de todo Gobierno el amparo y protección del individuo (...); el primer requisito incuestionable (de todo gobierno) debe ser esta protección a la libertad humana de manera precisa y clara, directa y necesaria (...); la constitución de un pueblo no debe procurar poner límites artificiales entre el Estado y el individuo como si se tratara de aumentar el campo a libre acción de uno (del Estado) y restringir la (capacidad de acción) del otro(individuo), de modo que lo que se da a uno sea la condición de la protección de lo que se reserva el otro (...). Se debe buscar que la autoridad concedida a los representantes (de gobiernos y empresas) no pueda convertirse en contra de la sociedad (Carranza, 1916, p. 5).

A partir de este postulado se establecen los cuatro ejes primarios de la Ley Federal del Trabajo, a saber: protección del individuo (garantías individuales), justicia social (inclusión), equidad e ingreso (Ley de Salarios Mínimos). 


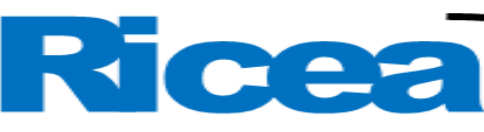

REVISTA IBEROAMERICANA DE CONTADURÍA, ECONOMÍA

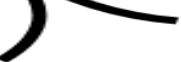

YADMINISTRACIÓN

El análisis realizado es un esquema comparativo entre la legislación inmediata anterior y la actual Ley Federal del Trabajo. Para ello, se identificaron aquellos elementos asociables a los aspectos de la calidad de vida en ambos marcos laborales, y se valorizó si el artículo en cuestión garantiza al trabajador la cobertura de sus necesidades básicas (calidad de vida) bajo el esquema desarrollado por Maslow.

\section{Ley Federal del Trabajo 1970}

De la Ley Federal del Trabajo decretada en 1970 se tomaron solo 14 artículos, pues se consideró que están explícitamente relacionados con los indicadores de calidad de vida, tal como se tenían definidos antes de las reformas laborales más significativas: Reforma Laboral 2012 (Inegi, 2000). Considerando como base los elementos identificados por Maslow, se definió como N1 a las necesidades básicas (fisiológicas y de seguridad), N2 a las necesidades psicológicas (afiliación y amor, y estima) y N3 a las necesidades de autorrealización (realización personal). En síntesis, por cada artículo se identificó al elemento que estaba cubriendo. La tabla 2 presenta esta identificación. 


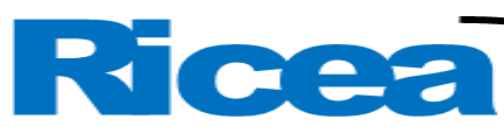

REVISTA IBEROAMERICANA DE CONTADURÍA, ECONOMÍA

Tabla 2. Necesidades de Maslow consideradas en la Ley Federal del Trabajo de 1970

\begin{tabular}{|c|c|c|}
\hline Artículo & Concepto & Nivel \\
\hline $\begin{array}{l}\text { Artículo } \\
3\end{array}$ & $\begin{array}{l}\text { El trabajo no es artículo de comercio. "Exige respeto para las libertades y } \\
\text { la dignidad de quien lo presta y debe efectuarse en condiciones que } \\
\text { aseguren la vida, la salud y un nivel económico decoroso para el trabajador } \\
\text { y su familia". }\end{array}$ & N1 \\
\hline $\begin{array}{l}\text { Artículo } \\
22\end{array}$ & $\begin{array}{l}\text { "Queda prohibida la utilización de los menores de } 14 \text { años y de los } \\
\text { mayores de esta edad y menores de dieciséis que no hayan terminado la } \\
\text { educación obligatoria". }\end{array}$ & N1 \\
\hline $\begin{array}{l}\text { Artículo } \\
47\end{array}$ & $\begin{array}{l}\text { Son causas de rescisión de la relación de trabajo, sin responsabilidad para } \\
\text { el patrón cuando en horario laboral, el trabajador: } \\
\text { "Falte de probidad u honradez, en actos de violencia, amagos, injurias o } \\
\text { malos tratamientos en contra del patrón, sus familiares o del personal } \\
\text { directivo o administrativo de la empresa o establecimiento, salvo que } \\
\text { medie provocación o que obre en defensa propia". }\end{array}$ & N3 \\
\hline $\begin{array}{l}\text { Artículo } \\
48\end{array}$ & $\begin{array}{l}\text { En el caso de un juicio: } \\
\text { "Si... el patrón no comprueba la causa de la rescisión, el trabajador tendrá } \\
\text { derecho }(. . .) \text { a que se le paguen los salarios vencidos desde la fecha del } \\
\text { despido hasta que se cumplimente el laudo". }\end{array}$ & N1 \\
\hline $\begin{array}{l}\text { Artículo } \\
50\end{array}$ & $\begin{array}{l}\text { Las indemnizaciones... } \\
\text { III. "Además de las indemnizaciones a que se refieren las fracciones } \\
\text { anteriores, en el importe de tres meses de salario y el de los salarios } \\
\text { vencidos desde la fecha del despido hasta que se paguen las } \\
\text { indemnizaciones". }\end{array}$ & N1 \\
\hline $\begin{array}{l}\text { Artículo } \\
93\end{array}$ & $\begin{array}{l}\text { Los trabajadores de campo, dentro de los lineamientos señalados en el } \\
\text { artículo } 90 \text { (salario mínimo), disfrutarán de un salario mínimo adecuado a } \\
\text { sus necesidades. }\end{array}$ & N1 \\
\hline $\begin{array}{l}\text { Artículo } \\
132\end{array}$ & $\begin{array}{l}\text { Obligaciones de los patrones } \\
\text { XVI... "Adoptarán los procedimientos adecuados para evitar perjuicios al } \\
\text { trabajador, procurando que no se desarrollen enfermedades epidémicas o } \\
\text { infecciosa, y organizando el trabajo de modo que resulte para la salud y la } \\
\text { vida del trabajador la mayor garantía compatible con la naturaleza de la } \\
\text { empresa o establecimiento". } \\
\text { XVI. Bis No existe } \\
\text { XVII. "Observar las medidas adecuadas y las que fijen las leyes, para } \\
\text { prevenir accidentes en el uso de maquinaria, instrumentos o material de } \\
\text { trabajo". }\end{array}$ & N1 \\
\hline $\begin{array}{l}\text { Artículo } \\
154\end{array}$ & $\begin{array}{l}\text { Adicionado en 1978: Si no existe contrato colectivo o no contiene cláusula } \\
\text { de admisión "los patrones estarán obligados a preferir, en igualdad de } \\
\text { circunstancias, a los trabajadores mexicanos respecto de quienes no lo } \\
\text { sean, a quienes les hayan servido satisfactoriamente por mayor tiempo, y a } \\
\text { los sindicalizados respecto de quienes no lo estén". }\end{array}$ & N1 \\
\hline $\begin{array}{l}\text { Artículo } \\
280\end{array}$ & $\begin{array}{l}\text { "Los trabajadores que tengan una permanencia continua de tres meses o } \\
\text { más al servicio de un patrón, tiene la presunción de ser trabajadores de } \\
\text { planta". }\end{array}$ & N1 \\
\hline $\begin{array}{l}\text { Artículo } \\
283\end{array}$ & $\begin{array}{l}\text { Los patrones tienen las obligaciones especiales siguientes: } \\
\text { II. "Suministrar gratuitamente a los trabajadores habitaciones adecuadas e } \\
\text { higiénicas, proporcionadas al número de familiares o dependientes }\end{array}$ & N1 \\
\hline
\end{tabular}




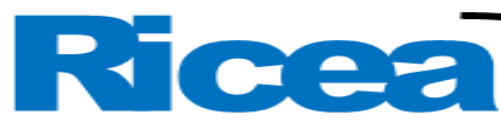

REVISTA IBEROAMERICANA DE CONTADURÍA, ECONOMÍA YADMINISTRACIÓN

ISSN $=2007-9907$

\begin{tabular}{|l|l|c|}
\hline & $\begin{array}{l}\text { económicos, y un terreno contiguo, para la cría de animales de corral". } \\
\text { V. "Proporcionar a los trabajadores y a sus familiares asistencia médica o } \\
\text { trasladarlos al lugar más próximo en el que existan servicios médicos". }\end{array}$ & \\
\hline $\begin{array}{l}\text { Artículo } \\
451\end{array}$ & $\begin{array}{l}\text { Para suspender los trabajos se requiere: } \\
\text { III. Que se cumplan previamente los requisitos señalados en el artículo } \\
\text { siguiente: }\end{array}$ & N2 \\
\hline $\begin{array}{l}\text { Artículo } \\
452\end{array}$ & $\begin{array}{l}\text { "Escrito de emplazamiento a huelga dirigida al patrón indicando las } \\
\text { peticiones y enviada a la JCA, con 6 días de anticipación o 10 en caso de } \\
\text { servicio público". }\end{array}$ & N2 \\
\hline $\begin{array}{l}\text { Artículo } \\
459\end{array}$ & $\begin{array}{l}\text { La huelga es legalmente inexistente si: } \\
\text { III. No se cumplieron los requisitos señalados en el artículo 452. }\end{array}$ & $\mathrm{N} 2$ \\
\hline $\begin{array}{l}\text { Artículo } \\
525\end{array}$ & $\begin{array}{l}\text { "La STyPS organizará un Instituto del Trabajo para la preparación y } \\
\text { elevación del nivel cultural para el personal técnico y administrativo". }\end{array}$ & $\mathrm{N} 2$ \\
\hline
\end{tabular}

Fuente: Elaboración propia

En la tabla anterior se observan 13 artículos dirigidos a proporcionar calidad de vida y bienestar, suficientes para alcanzar al menos dos elementos del mapa de desarrollo humano, mientras que existe un solo artículo dirigido a fomentar los valores (N3).

\section{Reforma laboral}

Se realiza el mismo ejercicio que en caso de la ley anterior; la tabla 3 presenta esta identificación.

Tabla 3. Necesidades de Maslow consideradas en la reforma de 2012 Ley Federal del Trabajo

\begin{tabular}{|c|l|c|c|}
\hline Artículo & \multicolumn{1}{|c|}{ Concepto } & Nivel \\
\hline \multirow{5}{*}{ Artículo 3 3} & $\begin{array}{l}\text { "Es de interés social promover y vigilar la capacitación, el } \\
\text { adiestramiento, la formación para y el trabajo, la certificación de } \\
\text { competencias laborales, la productividad y la calidad en el trabajo, la } \\
\text { sustentabilidad ambiental, así como los beneficios que éstas deban } \\
\text { generar tanto a los trabajadores como a los patrones". Artículo } \\
\text { reformado DOF 28-04-1978, 30-11-2012 }\end{array}$ & N3 \\
\hline \multirow{2}{*}{$\begin{array}{c}\text { Artículo 22bis: "Queda prohibido el trabajo de menores de quince años; } \\
\text { no podrá utilizarse el trabajo de mayores de esta edad y menores de } \\
\text { dieciocho años que no hayan terminado su educación básica obligatoria, } \\
\text { salvo los casos que apruebe la autoridad laboral correspondiente en que a } \\
\text { su juicio haya compatibilidad entre los estudios y el trabajo" Artículo } \\
\text { adicionado DOF 30-11-2012. Reformado DOF 12-06-2015 }\end{array}$} & N1+ \\
\hline Artículo & $\begin{array}{l}\text { Cuando en horario laboral, el trabajador "falte de probidad u honradez, } \\
\text { en actos de violencia, amagos, injurias o malos tratamientos en contra } \\
\text { del patrón, sus familiares o del personal directivo o administrativo de la } \\
\text { empresa o establecimiento, a clientes y proveedores del patrón, salvo que } \\
\text { medie provocación o que obre en defensa propia". } \\
\text { Fracción reformada DOF 30-11-2012 }\end{array}$ & N3- \\
\hline
\end{tabular}




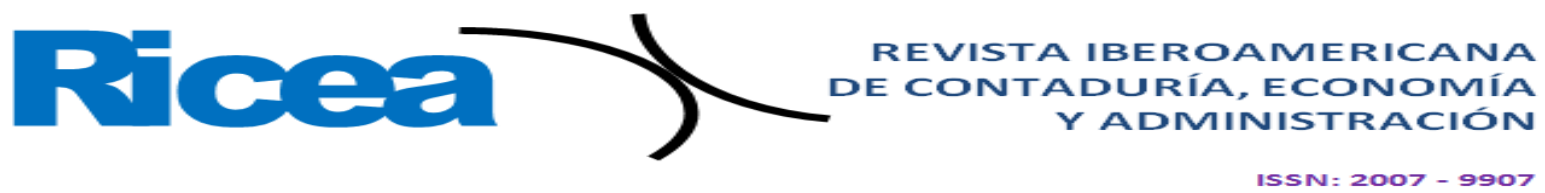

\begin{tabular}{|c|c|c|}
\hline $\begin{array}{c}\text { Artículo } \\
48\end{array}$ & $\begin{array}{l}\text { En el caso de un juicio } \\
\text { "Si... el patrón no comprueba la causa de la rescisión, el trabajador } \\
\text { tendrá derecho (...) a que se le paguen los salarios vencidos computados } \\
\text { desde la fecha del despido hasta un periodo máximo de doce meses. } \\
\text { Si al término del plazo señalado en el párrafo anterior no ha concluido el } \\
\text { procedimiento o no se ha dado cumplimiento al laudo, se pagarán } \\
\text { también al trabajador los intereses que se generen sobre el importe de } \\
\text { quince meses de salario, a razón del dos por ciento mensual, } \\
\text { capitalizable al momento del pago". Artículo reformado DOF 30-11- } \\
2012\end{array}$ & N1- \\
\hline $\begin{array}{c}\text { Artículo } \\
50\end{array}$ & $\begin{array}{l}\text { Las indemnizaciones... } \\
\text { III. "Además de las indemnizaciones a que se refieren las fracciones } \\
\text { anteriores, en el importe de tres meses de salario y el pago de los salarios } \\
\text { vencidos e intereses, en su caso, en los términos previstos en el artículo } \\
48 \text { de esta Ley". Fracción reformada DOF 30-11-2012 }\end{array}$ & N1- \\
\hline $\begin{array}{c}\text { Artículo } \\
93\end{array}$ & $\begin{array}{l}\text { Los salarios mínimos profesionales regirán para todos los trabajadores } \\
\text { de las ramas de actividad económica, profesiones, oficios o trabajos } \\
\text { especiales que se determinen dentro de una o varias áreas geográficas de } \\
\text { aplicación. Artículo reformado DOF 21-01-1988 }\end{array}$ & N3 \\
\hline $\begin{array}{c}\text { Artículo } \\
132\end{array}$ & $\begin{array}{l}\text { Obligaciones de los patrones } \\
\text { XVI... "Instalar y operar de acuerdo con las disposiciones establecidas } \\
\text { en el reglamento y las normas oficiales mexicanas en materia de } \\
\text { seguridad, salud y medio ambiente de trabajo, a efecto de prevenir } \\
\text { accidentes y enfermedades laborales. Asimismo, deberán adoptar las } \\
\text { medidas preventivas y correctivas que determine la autoridad laboral". } \\
\text { XVII. Cumplir el reglamento y las normas oficiales mexicanas en } \\
\text { materia de seguridad, salud y medio ambiente de trabajo. Fracción } \\
\text { reformada DOF 28-04-1978, 30-11-2012 }\end{array}$ & N3 \\
\hline $\begin{array}{c}\text { Artículo } \\
154\end{array}$ & $\begin{array}{l}\text { "Los patrones estarán obligados a preferir en igualdad de circunstancias } \\
\text { a los trabajadores mexicanos respecto de quienes no lo sean, a quienes } \\
\text { les hayan servido satisfactoriamente por mayor tiempo, a quienes no } \\
\text { teniendo ninguna otra fuente de ingreso económico tengan a su cargo } \\
\text { una familia, a los que hayan terminado su educación básica obligatoria, a } \\
\text { los capacitados respecto de los que no lo sean, a los que tengan mayor } \\
\text { aptitud y conocimientos para realizar un trabajo y a los sindicalizados } \\
\text { respecto de quienes no lo estén". Párrafo reformado DOF 30-11-2012 }\end{array}$ & N2 \\
\hline $\begin{array}{c}\text { Artículo } \\
280\end{array}$ & $\begin{array}{l}\text { "El trabajador estacional o eventual del campo que labore en forma } \\
\text { continua por un periodo mayor a veintisiete semanas para un patrón, } \\
\text { tiene a su favor la presunción de ser trabajador permanente". Artículo } \\
\text { reformado DOF 30-11-2012 }\end{array}$ & NA \\
\hline $\begin{array}{c}\text { Artículo } \\
283\end{array}$ & $\begin{array}{l}\text { Los patrones tienen las obligaciones especiales siguientes: } \\
\text { II. "Suministrar gratuitamente a los trabajadores habitaciones adecuadas } \\
\text { e higiénicas, proporcionales al número de familiares o dependientes } \\
\text { económicos que los acompañen y, en su caso, un predio individual o } \\
\text { colectivo, para la cría de animales de corral". } \\
\text { Fracción reformada DOF 30-11-2012 } \\
\text { VI. "Proporcionar a los trabajadores y a sus familiares que los } \\
\text { acompañen asistencia médica o trasladarlos al lugar más próximo en el }\end{array}$ & N1- \\
\hline
\end{tabular}




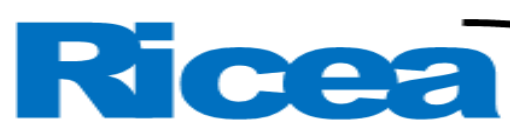

REVISTA IBEROAMERICANA DE CONTADURIAA, ECONOMIIA YADMINISTRACIÓN

ISSN $=2007-9907$

\begin{tabular}{|c|c|c|}
\hline & $\begin{array}{l}\text { que existan servicios médicos". } \\
\qquad \text { Fracción reformada y recorrida DOF 30-11-2012 }\end{array}$ & \\
\hline $\begin{array}{l}\text { Artículo } \\
\quad 451\end{array}$ & $\begin{array}{l}\text { Para suspender los trabajos se requiere: } \\
\text { III. Que se cumplan previamente los requisitos señalados en el artículo } \\
\text { siguiente: }\end{array}$ & $\mathrm{N} 2$ \\
\hline $\begin{array}{l}\text { Artículo } \\
452\end{array}$ & Se deroga Artículo derogado DOF 04-01-1980 & NA \\
\hline $\begin{array}{l}\text { Artículo } \\
459\end{array}$ & $\begin{array}{l}\text { La huelga es legalmente inexistente si: } \\
\text { III. No se cumplieron los requisitos señalados en el artículo } 452\end{array}$ & NA \\
\hline $\begin{array}{c}\text { Artículo } \\
525\end{array}$ & Se deroga Artículo derogado DOF 30-11-2012 & NA \\
\hline
\end{tabular}

Fuente: Elaboración propia

En este caso solo son seis artículos asociables a los indicadores del mapa de desarrollo. Un aspecto importante es que en la ley anterior eran 13, cuatro son nivel N3 y cuatro quedan sin efecto; de estos últimos, el artículo 280 da la pauta para que un trabajador eventual de campo pueda adquirir su calidad de trabajador de planta, pero se ve obstaculizado en cumplimiento del artículo 279 Ter, al indicar que el tiempo que un trabajador puede trabajar para un patrón o más no puede exceder lo que se requiere en el artículo 280. Además, se adicionaron artículos (emergentes) para factores que en la ley anterior no estaban considerados, por lo que no se pueden comparar. La tabla 4 presenta los artículos emergentes. 


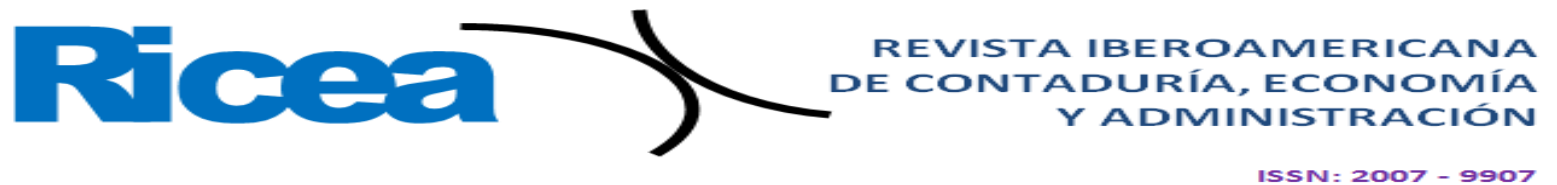

Tabla 4. Artículos emergentes de la reforma de 2012 a la Ley Federal del Trabajo

\begin{tabular}{|c|c|c|}
\hline Artículo & Concepto & Nivel \\
\hline $\begin{array}{c}\text { Artículo } \\
15^{\mathrm{a}}\end{array}$ & $\begin{array}{l}\text { Sobre el régimen de subcontratación: } \\
\text { "El trabajo en régimen de subcontratación es aquel por medio del cual } \\
\text { un patrón denominado contratista ejecuta obras o presta servicios con } \\
\text { sus trabajadores bajo su dependencia, a favor de un contratante, } \\
\text { persona física o moral, la cual fija las tareas del contratista y lo } \\
\text { supervisa en el desarrollo de los servicios o la ejecución de las obras } \\
\text { contratadas". } \\
\text { Este tipo de trabajo, deberá cumplir con las siguientes condiciones: } \\
\text { a) No podrá abarcar la totalidad de las actividades, iguales o similares } \\
\text { en su totalidad, que se desarrollen en el centro de trabajo. } \\
\text { b) Deberá justificarse por su carácter especializado. } \\
\text { c) No podrá comprender tareas iguales o similares a las que realizan el } \\
\text { resto de los trabajadores al servicio del contratante. } \\
\text { "De no cumplirse con todas estas condiciones, el contratante se } \\
\text { considerará patrón para todos los efectos de la Ley" Artículo } \\
\text { adicionado DOF 30-11-2012 }\end{array}$ & N3 \\
\hline $\begin{array}{c}\text { Artículo } \\
15 \mathrm{~B}\end{array}$ & $\begin{array}{l}\text { "El contrato que se celebre entre la persona física o moral que solicita } \\
\text { los servicios y un contratista, deberá constar por escrito". } \\
\text { "La empresa contratante deberá cerciorarse al momento de celebrar el } \\
\text { contrato a que se refiere el párrafo anterior, que la contratista cuenta } \\
\text { con la documentación y los elementos propios suficientes para cumplir } \\
\text { con las obligaciones que deriven de las relaciones con sus } \\
\text { trabajadores". Artículo adicionado DOF 30-11-2012 }\end{array}$ & N3 \\
\hline $\begin{array}{c}\text { Artículo } \\
15 \mathrm{C}\end{array}$ & $\begin{array}{l}\text { "La empresa contratante de los servicios deberá cerciorarse } \\
\text { permanentemente que la empresa contratista cumple con las } \\
\text { disposiciones aplicables en materia de seguridad, salud y medio } \\
\text { ambiente en el trabajo, respecto de los trabajadores de esta última". } \\
\text { "Lo anterior, podrá ser cumplido a través de una unidad de verificación } \\
\text { debidamente acreditada y aprobada en términos de las disposiciones } \\
\text { legales aplicables". } \\
\text { Artículo adicionado DOF 30-11-2012 }\end{array}$ & N3 \\
\hline $\begin{array}{c}\text { Artículo } \\
\text { 15D }\end{array}$ & $\begin{array}{l}\text { "No se permitirá el régimen de subcontratación cuando se transfieran } \\
\text { de manera deliberada trabajadores de la contratante a la subcontratista } \\
\text { con el fin de disminuir derechos laborales". } \\
\text { Artículo adicionado DOF 30-11-2012 }\end{array}$ & N1 \\
\hline $\begin{array}{c}\text { Artículo } \\
153 \mathrm{~A}\end{array}$ & $\begin{array}{l}\text { "Los patrones tienen la obligación de proporcionar a todos los } \\
\text { trabajadores, y éstos a recibir, la capacitación o el adiestramiento en su } \\
\text { trabajo que le permita elevar su nivel de vida, su competencia laboral y } \\
\text { su productividad, conforme a los planes y programas formulados". } \\
\text { Artículo adicionado DOF 28-04-1978. Reformado DOF 30-11-2012 }\end{array}$ & N3 \\
\hline $\begin{array}{l}\text { Artículo } \\
279 \text { Ter }\end{array}$ & $\begin{array}{l}\text { "Los trabajadores estacionales del campo o jornaleros son aquellas } \\
\text { personas físicas que son contratadas para laborar en explotaciones } \\
\text { agrícolas, ganaderas, forestales, acuícolas o mixtas, únicamente en } \\
\text { determinadas épocas del año... Puede ser contratada por uno o más } \\
\text { patrones durante un año, por periodos que en ningún caso podrán ser } \\
\text { superiores a veintisiete semanas por cada patrón". }\end{array}$ & N3 \\
\hline
\end{tabular}




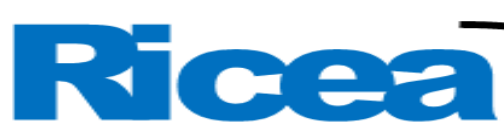

REVISTA IBEROAMERICANA DE CONTADURÍA, ECONOMÍA Y ADMINISTRACIÓN

$15 S N=2007-9907$

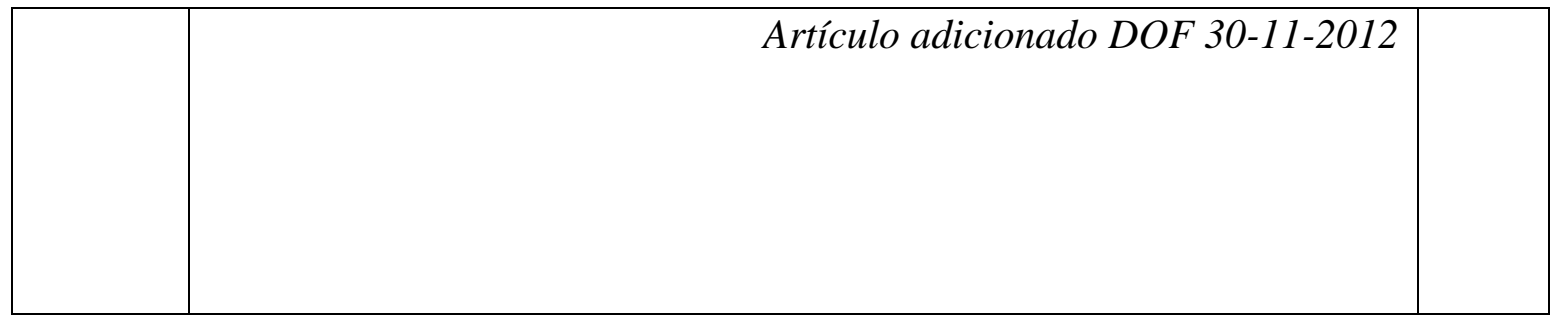

Fuente: Elaboración propia

Como puede notarse, los artículos emergentes están dirigidos al nivel terciario: la trascendencia y autorrealización del individuo, con lo que se dejan de lado los indicadores de calidad de vida. Solo el artículo 15D se consideraría de nivel primario, pero careciendo de importancia por lo especificado en el artículo 15A último párrafo.

La tabla de enfermedades de trabajo hasta el momento incluye 161 padecimientos, los cuales en algunos casos dejan la ventana abierta para que se aplique en diversos puestos laborales, aunque en otros están acotados a unas cuantas áreas laborales. Solo para mencionar algunas situaciones, en el caso de dermatosis considera las enfermedades de la piel provocadas por agentes mecánicos, físicos, químicos inorgánicos u orgánicos, o biológicos; queda fuera la dermatitis provocada por estrés, una de las consecuencias de trabajos con actividades de alta presión. La neurosis la deja abierta para puestos similares a los pilotos aviadores o telefonistas, con lo que se puede sobreentender que se aplica a puestos de trabajo de la aviación o centro de llamadas, aunque también puede significar puestos que trabajan bajo presión o de mucha responsabilidad. Igual sucede con el complejo cutáneo vascular de pierna que indica algunas profesiones y sus similares. En el caso del tétanos solo menciona siete profesiones. Sobre enfisema pulmonar por factores mecánicos, solo a músicos de instrumentos de viento y sopladores de vidrio. En cuanto a tuberculosis, brucelosis, tétanos, virosis, también está limitado a puestos de trabajo de hospitales, laboratorios, ganaderos, veterinarios, a pesar de que existen otros puestos de trabajo cuyas condiciones pueden poner en riesgo la adquisición de estas enfermedades, por lo que estás limitaciones o falta de ellas pueden abrir la posibilidad de exceptuar la declaratoria de enfermedad de trabajo para algún empleado y su debida incapacidad con responsabilidad para el patrón.

La tabla de validación de incapacidades permanente fue retirada de la ley para ser publicada en el Diario Oficial de la Federación [Dof] (2018), para lo cual se creó la Comisión Consultiva Nacional de Seguridad y Salud en el Trabajo [Ccsst], cuya función es coadyuvar en la definición de políticas públicas referentes a seguridad, salud y medio ambiente en el trabajo, lo cual da facultad de opinar sobre dicha tabla. 


\section{Discusión}

En esencia, ambas leyes comparten diez artículos (3, 22, 47, 48, 50, 93, 132, 154, 280 y 283) referentes a la preservación del bienestar del trabajador en nivel N1, pero fueron reformados. Los cambios evidentes se hallan en que pasan de cubrir necesidades básicas (N1) a necesidades terciarias (N3); del primer nivel en 1970 había 10 y solo un nivel 3, en 2012 hay cuatro nivel 1, pero con garantías disminuidas como el límite al tiempo de cobertura salarial al que tiene derecho el trabajador en un proceso de demanda ante un despido justificado (artículos 48 y 50), lo que vulnera más al trabajador al reducir el margen de seguridad de no ser despedido, considerando su tiempo en la empresa, pues al determinar un tope de salarios vencidos durante un laudo, no importa la antigüedad, o la presunción de trabajador de planta para un trabajador de campo mencionado en los resultados (artículo 280), que ya no lo logrará ser. El artículo 47 aumentó el margen de acción de las empresas para realizar despidos sin recaer en responsabilidad jurídica. Solo el artículo 22 incrementó las garantías para evitar el trabajo infantil al elevar la edad mínima para trabajar, y aumentó a cinco en nivel 3.

Hay una pérdida de $60 \%$ en los indicadores de calidad de vida (nivel primario), y un incremento de $400 \%$ en el nivel terciario, y se elimina todo un indicador de calidad de vida a través de la derogación. En la tabla 5 se tienen las diferencias que resultan de comparar los artículos, de este nivel, de la Ley Federal (1970) y la resultante de las reformas de 2018, que para el caso de las que competen en el estudio se dieron en el año 2012.

Tabla 5. Comparativo de cobertura de necesidades. Ley Federal de Trabajo 1970 y sus reformas a 2012

\begin{tabular}{|l|c|c|}
\hline \multirow{2}{*}{ Artículo } & \multicolumn{2}{|c|}{ Nivel } \\
\cline { 2 - 3 } & 1970 & 2012 \\
\hline Artículo 3 & $\mathrm{N} 1$ & $\mathrm{~N} 3$ \\
\hline Artículo 22 & $\mathrm{N} 1$ & $\mathrm{~N} 1+$ \\
\hline Artículo 47 & $\mathrm{N} 3$ & $\mathrm{~N} 3-$ \\
\hline Artículo 48 & $\mathrm{N} 1$ & $\mathrm{~N} 1-$ \\
\hline Artículo 50 & $\mathrm{N} 1$ & $\mathrm{~N} 1-$ \\
\hline Artículo 93 & $\mathrm{N} 1$ & $\mathrm{~N} 3$ \\
\hline Artículo 132 & $\mathrm{N} 1$ & $\mathrm{~N} 2-$ \\
\hline Artículo 154 & $\mathrm{N} 1$ & $\mathrm{~N} 2$ \\
\hline Artículo 280 & $\mathrm{N} 1$ & $\mathrm{NA}$ \\
\hline Artículo 283 & $\mathrm{N} 1$ & $\mathrm{~N} 3$ \\
\hline
\end{tabular}

Nota: El signo negativo significa que el artículo, aun contemplando la cobertura de dicho nivel de necesidad, se vio disminuido en garantías y el positivo que las incrementó.

Fuente: Elaboración propia a partir de las tablas 2 y 3 


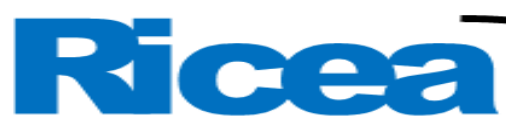

REVISTA IBEROAMERICANA DE CONTADURÍA, ECONOMIIA

Respecto a los artículos que no aparecen en la tabla anterior, tenemos que son 11: seis son de nueva creación (tabla 4) y cinco dejan de surtir efecto (Tabla 6).

Tabla 6. Artículos

\begin{tabular}{|l|c|c|}
\hline \multirow{2}{*}{\multicolumn{1}{|c|}{ Artículo }} & \multicolumn{2}{|c|}{ Nivel } \\
\cline { 2 - 3 } & 1970 & 2012 \\
\hline Artículo 15A & No existe & N3 \\
\hline Artículo 15B & No existe & N3 \\
\hline Artículo 15C & No existe & N3 \\
\hline Artículo 15D & No existe & N1 \\
\hline Artículo 132 BIS & No existe & N1 \\
\hline Artículo 153A & No existe & N3 \\
\hline Artículo 279 Ter & N2 & No tiene efecto \\
\hline Artículo 451 & $\mathrm{N} 2$ & Desaparece \\
\hline Artículo 452 & $\mathrm{N} 2$ & Desaparece \\
\hline Artículo 459 & $\mathrm{N} 1$ & Desaparece \\
\hline Artículo 525 & $\mathrm{N} 2$ & Desaparece \\
\hline
\end{tabular}

Fuente: Elaboración propia a partir de la tabla 4

Como se aprecia, se elimina un artículo asociado a la calidad de vida y se agregan seis en la reforma de 2012 a favor de la subcontratación (ahora denominada outsourcing), que si bien existía antes de dicha reforma, se le dio más respaldo legal para que en la actualidad sea práctica común en todo tipo de empresas, incluso de Gobierno, lo que no cubre la totalidad de los indicadores de calidad de vida, con lo que se espera una autorrealización automática del trabajador derivada de la posesión de un empleo.

En el caso de bienestar (N2), los artículos asociados desaparecen o se dejan sin efecto, con lo cual se disminuye la calidad de vida a favor de la autorrealización. Asimismo, hay una pérdida de elementos de protección al trabajador en los artículos 451, 452, 459 y 525 al quedar derogados, los cuales están relacionados con el derecho del bienestar y la protección del núcleo familiar.

Otro aspecto de suma relevancia es que en 1980 los artículos 451 y 452 son cancelados: el primero sin efecto automático al ser anulado el segundo, y ambos están relacionados con el derecho de huelga. Se modifica el lenguaje para desaparecer el concepto huelga, que es sustituido por suspensión de labores, lo que lleva a una contradicción en la ley actual: en el artículo 451 se especifica que la huelga es legalmente inexistente si no se cumplen los requisitos del artículo 452, el cual, a su vez, ha sido derogado. 


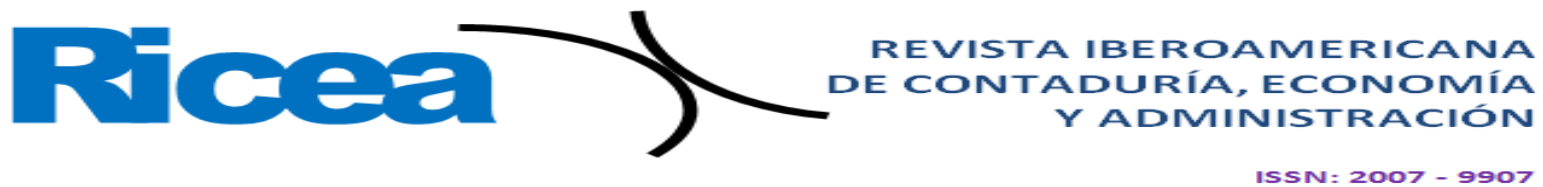

Respecto a la normatividad internacional, existen diversos espacios de protección al trabajador; uno de ellos es el Sistema Universal de Protección de los Derechos Humanos con el Pacto Internacional de Derechos Económicos, Sociales y Culturales por medio de los cuales se pretende alcanzar una igualdad material que satisfaga las necesidades básicas de las personas y provea el máximo nivel posible de vida digna. México es uno de los países adherentes desde 1981, donde se establece como un derecho el acceso al trabajo bajo las siguientes condiciones:

- El goce de condiciones de trabajo equitativas y satisfactorias que le aseguren un salario suficiente, equitativo e igual por trabajo de igual valor (N1).

- Condiciones de existencia dignas para ellos y para sus familias, lo que obliga a que el salario sea capaz de proveer un nivel de vida adecuado para sí y su familia, incluso alimentación, vestido y vivienda adecuados (N1, N2).

- Conceder a la familia la más amplia protección y asistencia posibles; especial protección a las madres antes y después del parto $(\mathrm{N} 1, \mathrm{~N} 2)$.

- El disfrute del tiempo libre, la limitación razonable de las horas de trabajo y las vacaciones periódicas pagadas, así como la remuneración de los días festivos (N2).

- Una mejora continua de las condiciones de existencia (N2).

- Igual oportunidad para todos de ser promovidos sin más consideraciones que los factores de tiempo de servicio y capacidad (N3).

Por otra parte, el ingreso se define como el ingreso a la paga en efectivo y en otras formas que percibe al menos un miembro de un hogar. Este debe ser periódico y no abarca ingresos imprevistos. En México, además, se considera que debe ser suficiente para cubrir las necesidades del trabajador y su familia.

De acuerdo con la Organización Internacional del Trabajo, el umbral internacional de pobreza establecido por el Banco Mundial es de US\$1.90/día. Esto significa que si un trabajador recibe un salario menor a este límite, no será capaz de cubrir sus necesidades ni las de su familia, por lo que su calidad de vida será baja o nula, por lo que no tendrá bienestar. En México, \$1.90 dólares equivale a $\$ 36.27$ pesos mexicanos, según un tipo de cambio de $\$ 19.08$ pesos por dólar (cotización de noviembre de 2019) (Gobierno de México, 2018).

El salario mínimo diario general vigente en México a partir del 1 de enero del mismo año es de $\$ 102.68$, lo que significa que en el país los empleos, por ley, son pagados por encima de la línea de pobreza; sin embargo, y en franca contradicción, estos salarios no son suficientes para cubrir las necesidades de un empleado y su familia. Esto significa que a pesar de que el salario 


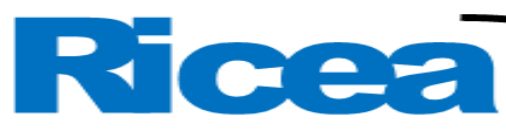

REVISTA IBEROAMERICANA DE CONTADURÍA, ECONOMIA YADMINISTRACIÓN

ISSN $=2007-9907$

esté por encima de la línea de pobreza, no es el único elemento que se debe considerar para catalogar un trabajo como digno, suficiente y/o decente. La Ocde (2013), en su estudio How's life estima que el bienestar en el lugar de trabajo es indispensable, ya que no solo se trata de tener un empleo, sino de que este aporte satisfacción de vida (N3) en las personas, es decir, que suministre elementos de nivel terciario. En otras palabras, se debe tomar en cuenta el tipo de trabajo, el sueldo y las condiciones de seguridad laboral, así como la interacción con colegas y la empresa.

En particular, la seguridad laboral se refiere al tipo de contrato (eventual o planta), lo que determina la estabilidad laboral; es decir, un sueldo periódico que ofrezca al empleado la certidumbre respecto a la capacidad de pagar los elementos de calidad de vida, lo cual le otorgará la estabilidad social. La combinación de ambos aspectos permite al trabajador desarrollar una vida decente. Existen factores adicionales como asistencia social, beneficios familiares y de vivienda, que determinan la calidad en el empleo y son cruciales para que un trabajador opte por él. En contraparte, un empleo precario se define por tener pocas horas de trabajo, pago diferenciado por hora entre trabajadores de tiempo completo, bajos salarios, ausencia de prestaciones, falta se seguridad laboral o abuso y/o ausencia de derechos laborales y humanos.

Finalmente, recuérdese que el neoliberalismo se unió a la globalización llevando todos estos conceptos al mayor número de países posibles; sin embargo, derivado de la pérdida de la calidad de empleo a nivel global, se inició un proceso de pauperización sistemática, que lleva a su vez a la migración de grandes sectores poblacionales de países pobres hacía los países que ofrecen mejores empleos.

Este fenómeno impacta a los países desarrollados debido a que se convierten en las regiones objetivo de los flujos migratorios. En un esfuerzo por comprender y frenar dichos flujos, organismos internacionales han desarrollado indicadores para análisis de la situación cualitativa de vida en los países, que incluye el aspecto laboral de manera muy puntual. Del grueso de programas se han elegido ocho vinculados con la calidad de vida y del trabajo (Tabla 7). 


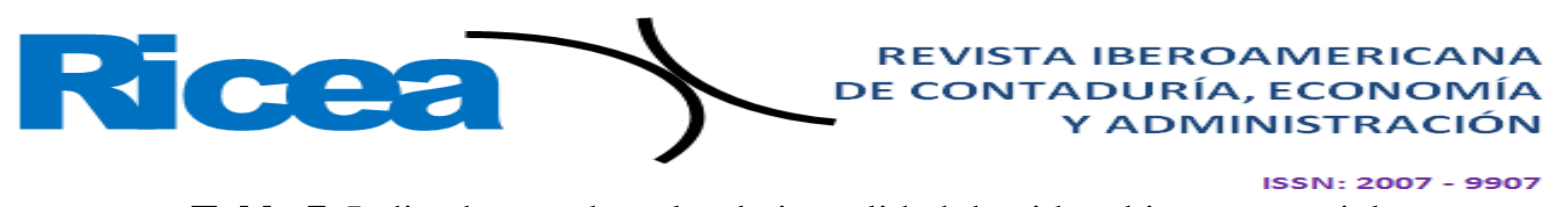

Tabla 7. Indicadores sobre el trabajo, calidad de vida y bienestar social

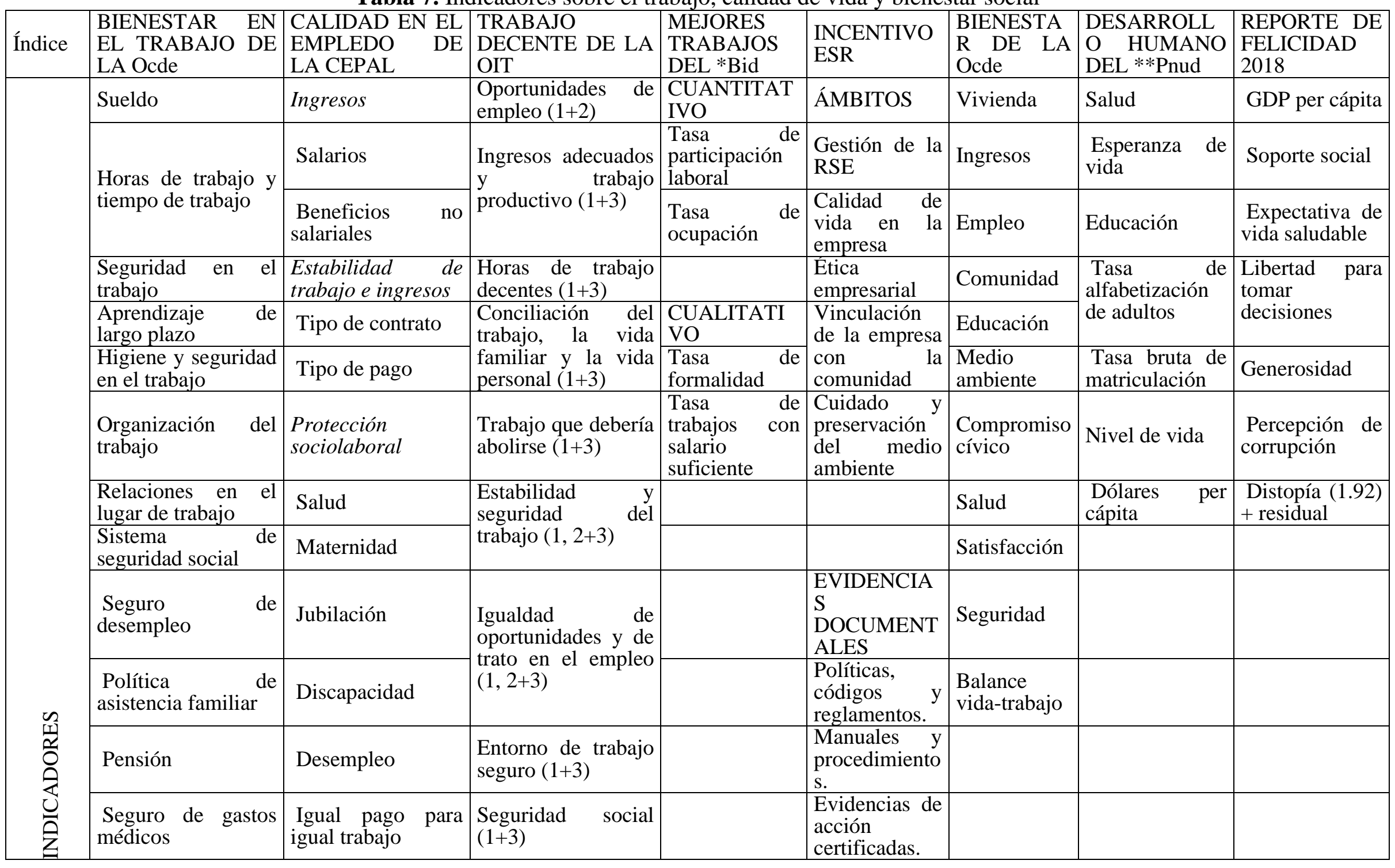

\section{Vol. 10, Núm. 19 Enero - Junio 2021}




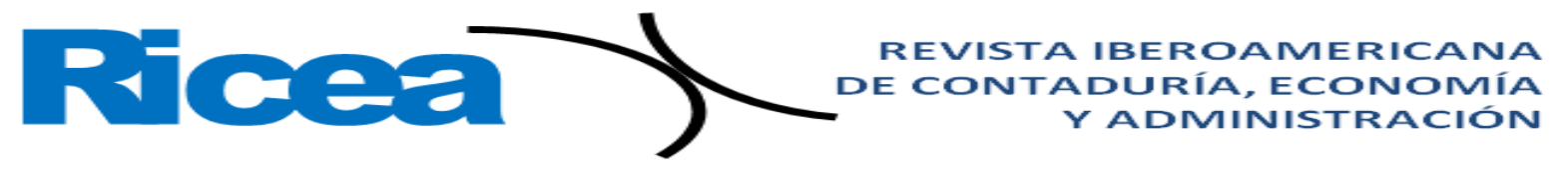

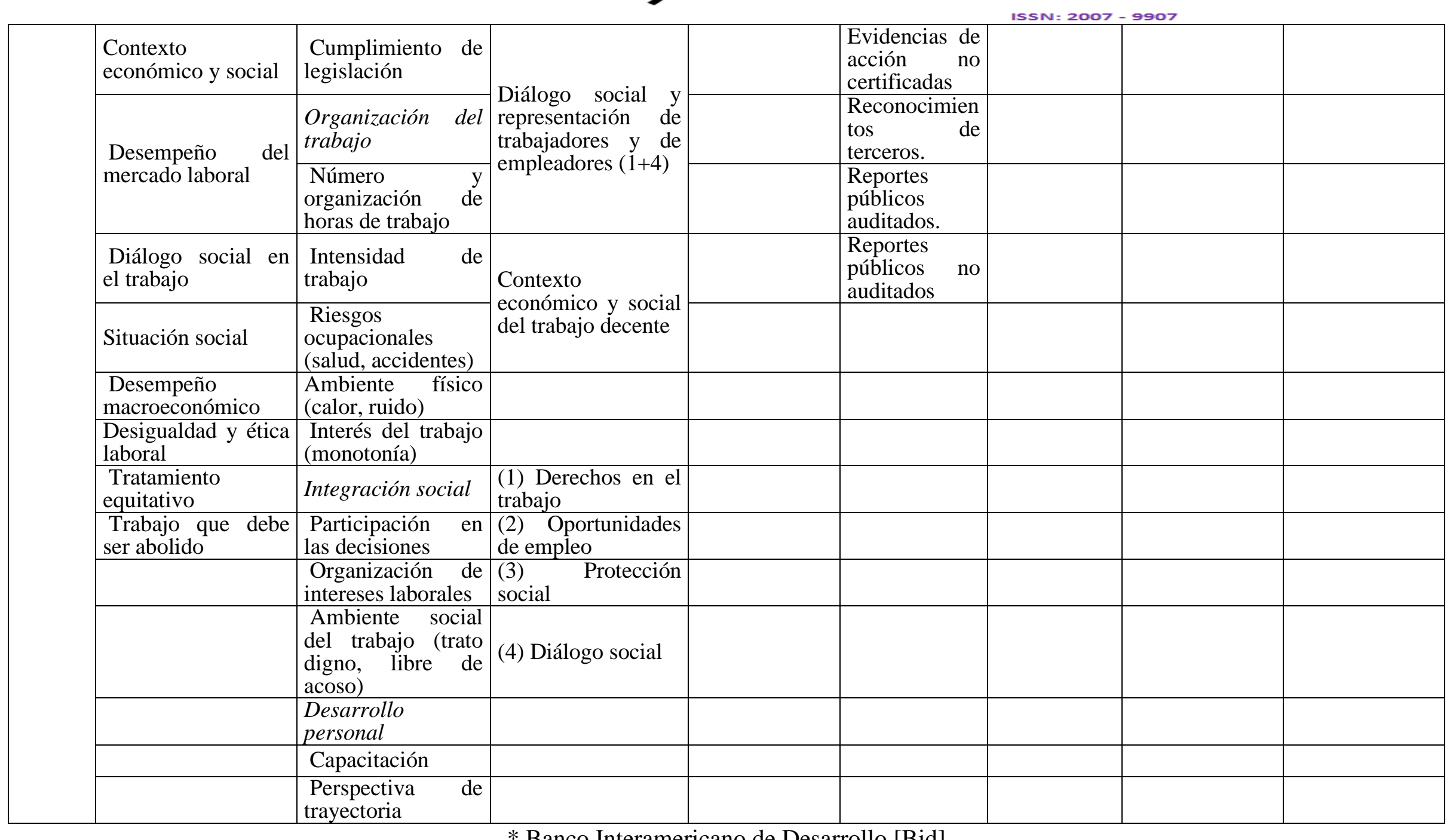

* Banco Interamericano de Desarrollo [Bid]

**Programa de las Naciones Unidas para el Desarrollo [Pnud]

Fuente: Elaboración propia

\section{Vol. 10, Núm. 19 Enero-Junio 2021}




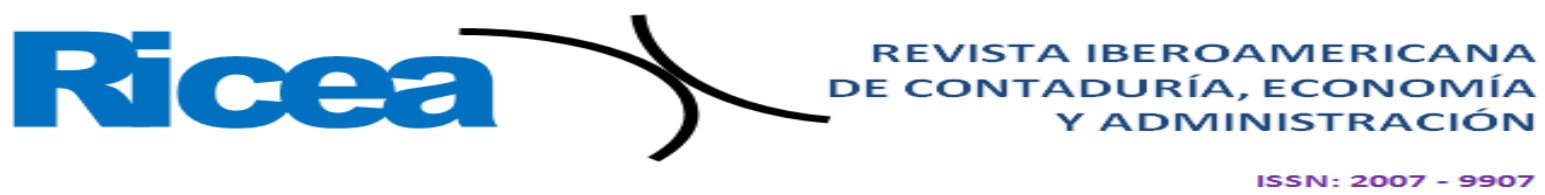

Los relacionados al trabajo que pueden tomarse como referentes para mejorar las condiciones laborales son el de bienestar en el trabajo de la Ocde, calidad en el empleo de la Cepal y trabajo decente de la OIT, que consideran la cobertura de necesidades básicas al mismo nivel que la estima y autorrealización. En los restantes, aunque su título implica el concepto de mejora de condiciones, los resultados son pobres porque su construcción es totalmente perceptiva, y no abarcan los conceptos de calidad de vida y bienestar, necesarios para el desarrollo del individuo. Finalmente, el índice de mejores trabajos del Banco Interamericano de Desarrollo se limita al análisis general de la situación del mercado laboral desde la perspectiva de las empresas y nivel macro, con lo que se da peso a las condiciones de precariedad de forma global.

\section{Conclusiones}

En el año 2012 se realizaron cambios significativos a la ley laboral de México que no solo han impactado en las calificaciones internacionales que ha logrado el país en materia de competencia laboral, sino que también se han convertido en tema de discusión para la firma de convenios con otros países, como el Tratado entre México, Estados Unidos y Canadá [T-Mec].

En tal sentido, en la comparación realizada en el presente trabajo entre la legislación anterior y la actual se encontró que la primera cubría nueve de las nueve variables consideradas para la evaluación de la calidad de vida de la Organización de las Naciones Unidas [Onu] (1961), mientras que la nueva legislación solo cubre cinco, y de manera reducida. Además, comparando estos hallazgos con los indicadores de las organizaciones internacionales (segundo objetivo de este documento), se encontró que existe una gran distancia entre ellos. Todo este cambio es la base de la competitividad desarrollada a partir del año 2000 con el objetivo de atraer mayores inversiones al país al prometerles mayores ganancias a las empresas a partir de la precarización del empleado.

En el caso de México, el Gobierno en su afán de dar un marco de desarrollo a nivel país realizó el cambio de leyes a favor de la empresa. Desde esta postura se redujeron o eliminaron en la reforma de ley los elementos a favor de la calidad de vida para eliminar gastos asociados con a) la subsistencia del empleado y b) la construcción y fortalecimiento del capital humano de la empresa.

El incremento de las ganancias, en consecuencia, no proviene de la generación de bienes y servicios o de una mejor calidad de servicios/productos, sino de la sustracción de volúmenes de dinero de los espacios de la cadena de valor asociados al empleado. Concretamente, la reforma a 


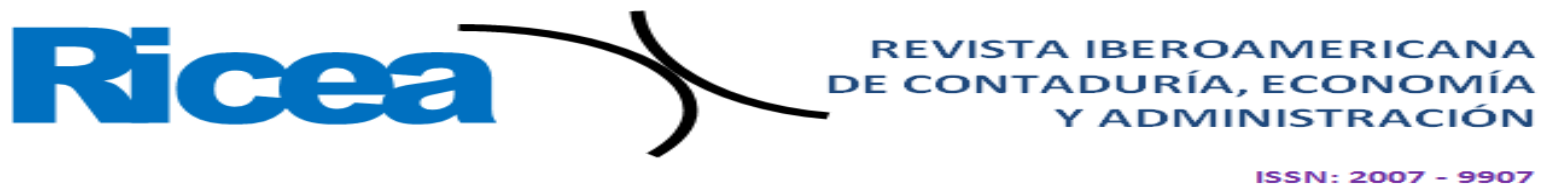

la ley laboral se traduce en falta de seguridad del empleo, con la figura de subcontratación que elimina a) certeza en el empleo y b) todos los elementos adicionales que mejoran la calidad de vida y bienestar, como seguridad social, apoyo a alimentación y vivienda.

La comparación hecha entre la legislación inmediata anterior y la actual Ley Federal del Trabajo permite evidenciar que los elementos considerados en el nuevo marco laboral no garantizan que el trabajador pueda cubrir las necesidades básicas para obtener calidad de vida, según el esquema desarrollado por Maslow, pues se pasó de una medición concreta del nivel de vida basada en salud, nutrición, educación, empleo, condiciones de trabajo, vivienda, seguridad social, vestido, esparcimientos y libertades humanas a una apertura del mercado al entorno internacional sustentada por un índice para una vida mejor [Ocde] y basada en indicadores macroeconómicos y aspectos externos como medio ambiente, seguridad, compromiso cívico y satisfacción con la vida. En definitiva, se asumió el discurso de que una alta competitividad en el ámbito privado es la base para el ámbito público.

De todo lo anterior se desprende que la actual ley da por sentado que el trabajador tiene cubiertas las necesidades primarias (N1), por lo que se esperan resultados del nivel 3 (autorrealización); sin embargo, el Gobierno tampoco provee los elementos de la base, de ahí que esta política pública de la competitividad provoque asimetrías económico-laborales cuyo reflejo lo tenemos en la sistemática pauperización de las comunidades receptoras de industrias maquiladoras y de extracción de recursos, que se han convertido en regiones expulsoras de recursos humanos. Dicho de otra forma: el Estado ha abandonado al trabajador en esta confronta por el equilibrio en las relaciones obrero-patronales.

Finalmente, tomando como base lo enseñado en la tabla 7, notamos que las instancias internacionales han retomado los indicadores de calidad de vida que hace 25 años se eliminaron en aras de la competitividad económica. Al parecer, los efectos de la globalización (pobreza, migración forzada, enfrentamientos armados por la tutela de recursos naturales, economía formal estancada y crecimiento de la economía ilegal) han obligado a un análisis del modelo macroeconómico vigente para impulsar uno nuevo de políticas públicas internacionales sustentado en un índice para una vida mejor (Ocde, 2013), el cual se basa en educación, vivienda, empleo y en indicadores macroeconómicos y aspectos externos como medio ambiente, seguridad, compromiso cívico y satisfacción con la vida, es decir, la conjunción de los universos microeconómico y macroeconómico.

México ha adoptado parte de estos indicadores, pero no inciden sobre la calidad del 


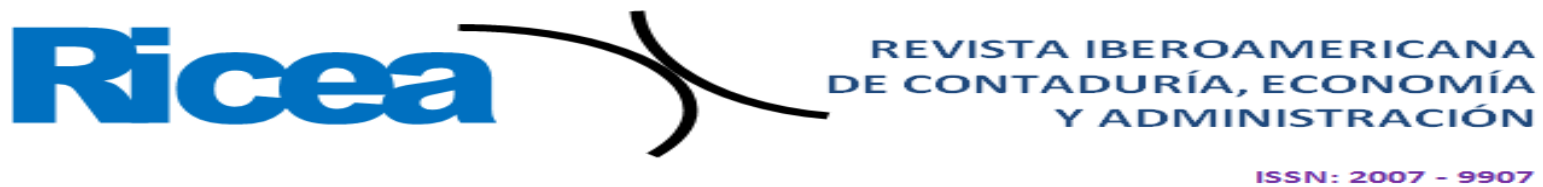

empleo de forma práctica. De hecho, si se comparan estos con la ley de 1970, ambos contienen lo necesario para que el trabajador cubra sus necesidades de niveles básicos y de filiación, y por ende cubriría los de autorrealización. La tendencia actual en materia laboral es regresar al esquema anterior, recalcando que el empleo debería "asegurar un estándar adecuado de vida para los trabajadores y sus familias" (OIT 2007 en Bid, 2017, p. 3).

Esto significa que la construcción del espacio de desarrollo integral y de bienestar depende de los indicadores de calidad de vida (N1) y de bienestar (N2), pero la aprobación de las reformas estructurales en la búsqueda de ser un país competitivo fue a costa del detrimento de las condiciones laborales. En definitiva, esta política pública fue capaz de atraer inversión extranjera, pero se dejó de ver al trabajador como ser humano para considerarlo como factor de producción.

\section{Futuras líneas de investigación}

A partir de los efectos de pauperización del trabajador, en el año 2019 la actual administración federal ha realizado reformas en el sector para cumplir con tratados internacionales como el T-Mec, donde sobresalen las modificaciones siguientes:

1. Desaparición de la Junta de Conciliación y Arbitraje para establecer tribunales en cada entidad federativa, con concursos abiertos para designar a los titulares.

2. Creación de un Centro Federal de Conciliación y Registro Laboral que se encargará de asuntos relacionados con los sindicatos y de procesos conciliatorios a nivel federal, separando la función conciliadora (autoridades administrativas) de la judicial.

3. Revisión de contratos colectivos y obligatoriedad de su contenido en el Centro Federal de Conciliación y Registro Laboral y entregado a todos los trabajadores.

4. Seguridad social y derecho de sindicato para el trabajador doméstico, y también derecho de sindicato de patrones.

5. Reforzamiento de elementos de oralidad y uso de tecnologías en procesos laborales, reduciendo tiempos procesales, con exigencia de permanencia de juez en audiencias, y con derecho las partes a interrogar a testigos libremente sin que se someta a preguntas por escrito del órgano jurisdiccional.

6. Creación de la Constancia de representatividad sindical, que indicará que los trabajadores respaldan las decisiones de los sindicatos en la ejecución de derechos colectivos (huelga, contrato colectivo, etc.).

7. Aviso por escrito de despido a los trabajadores. 


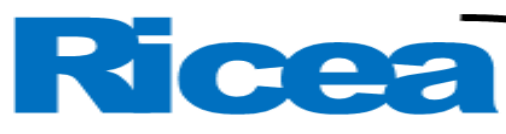

REVISTA IBEROAMERICANA DE CONTADURÍA, ECONOMÍA YADMINISTRACIÓN

ISSN= $2007-9907$

Estas acciones son parte de las reformas de 2017 dirigidas a cumplir con los tratados internacionales (T-Mec). Si bien suponen alguna protección para el trabajador, no consideran los elementos base de calidad de vida y bienestar, por lo que no representan una mejora real para el individuo. En este contexto, se espera continuar con la evaluación de las condiciones laborales según se vayan ejecutando las metas planteadas en la reforma.

\section{Referencias}

Banco Interamericano de Desarrollo [Bid]. (2017). Índice de Mejores Trabajos: Índice de Condiciones Laborales de América Latina. Nota Técnica. IDB-TN-1326. Estados Unidos. https://publications.iadb.org/publications/spanish/document/\%C3\%8Dndice-deMejores-Trabajos-\%C3\%8Dndice-de-Condiciones-Laborales-de-Am\%C3\%A9ricaLatina.pdf

Cajiga, J. F. (2010). El concepto de responsabilidad social empresarial. México: Cemefi. http://www.cemefi.org/esr/images/stories/pdf/esr/concepto_esr.pdf

Carpizo, J. (1982). Diccionario jurídico mexicano. México: Instituto de Investigaciones Jurídicas, UNAM.

Carranza, V. (1916). Diario de Debates del Congreso Constituyente. Estados Unidos Mexicanos. Periodo Único, Querétaro, Qro., $1^{\circ}$ de diciembre, Tomo I, (12), 260-270. https://www.constitucion1917-

2017.pjf.gob.mx/sites/default/files/CPEUM_1917_CC/DVC_1916.PDF

Diario Oficial de la Federación. (1 de abril de 1970). Ley Federal del Trabajo. Tomo CCXCIX, (26). México.

Diario Oficial de la Federación. (2018). Ley Federal del Trabajo. Última reforma publicada en el DOF el 22-06-2018.

Finkelstein J. (s. f.) Representación de la jerarquía de necesidades de Maslow: Pirámide de Maslowo Diagrama de Maslow (traducido por Mikel Salazar González). https://commons. wikimedia.org/w/index.php?curid=2696674

Foucault, M. (2010). Neoliberalismo y biopolítica. Edición de Vanesa Lemm. Ediciones Universidad Diego Portales (UDP). http://www.scielo.org.co/pdf/tara/n14/n14a16.pdf

Freeman R. E., Harrison S. J. y Stelios Zyglidopoulos. (2010). Stakeholder Theory. The state of the art. Cambridge University Press. USA.

Galván, F. A. y Guadarrama, B. M. E. (2017). Una visión alternativa de las políticas públicas. 


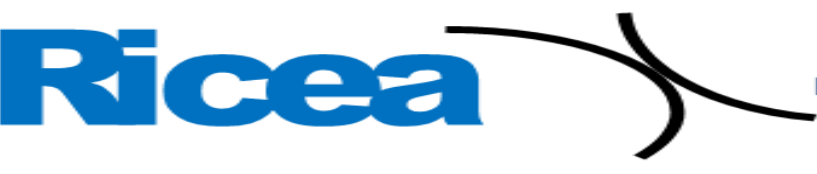

Administración Contemporánea. Revista de Investigación, 10(33), (pp.78-97).

Gobierno de México (2018). Resolución del salario mínimo vigente para 2019. https://www.gob.mx/stps/prensa/publica-diario-oficial-de-la-federacion-la-nuevapolitica-de-salarios-minimos

Instituto Nacional De Estadística Geografía e Informática [Inegi]. (2000). XII Censo general de población y vivienda. México: Instituto Nacional de Estadística, Geografía e Informática.

Organización de las Naciones Unidas [Onu]. (1961). Definición y medición internacional del nivel de vida. Guía provisional. Nueva York: Organización de las Naciones Unidas.

Organización para la Cooperación y el Desarrollo Económicos [Ocde]. (2013). Well-being in the workplace: Measuring job quality. París: OECD Publishing, http://dx.doi.org/10.1787/how_life-2013-9-en 


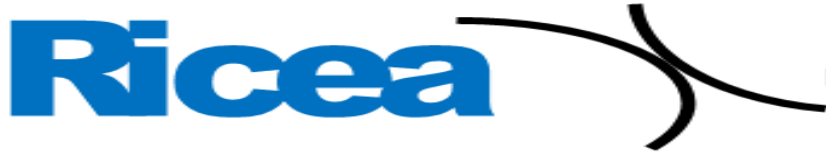

REVISTA IBEROAMERICANA DE CONTADURÍA, ECONOMIIA

\begin{tabular}{|c|c|}
\hline Rol de Contribución & Autor (es) \\
\hline Conceptualización & $\begin{array}{l}\text { Antonina Galván Fernández principal } \\
\text { Elsa Pacheco Luis Apoyo }\end{array}$ \\
\hline Metodología & $\begin{array}{l}\text { Antonina Galván principal } \\
\text { Elsa Pacheco Luis apoyo }\end{array}$ \\
\hline Software & No aplica \\
\hline Validación & $\begin{array}{l}\text { Gabriela Escobedo Guerrero Principal } \\
\text { Antonina Galván Fernández igual }\end{array}$ \\
\hline Análisis Formal & Elsa Pacheco Luis Principal \\
\hline Investigación & $\begin{array}{l}\text { Elsa Pacheco Luis Principal } \\
\text { Antonina Galván Fernández apoyo }\end{array}$ \\
\hline Recursos & Antonina Galván Fernández principal \\
\hline Curación de datos & $\begin{array}{l}\text { Gabriela Escobedo Guerrero Principal } \\
\text { Antonina Galván igual }\end{array}$ \\
\hline $\begin{array}{l}\text { Escritura - Preparación del } \\
\text { borrador original }\end{array}$ & Elsa Pacheco Luis principal \\
\hline $\begin{array}{l}\text { Escritura - Revisión y } \\
\text { edición }\end{array}$ & $\begin{array}{l}\text { Antonina Galván Fernández principal } \\
\text { Eva Guadarrama Brito apoyo }\end{array}$ \\
\hline Visualización & $\begin{array}{l}\text { Antonina Galván Fernández Principal } \\
\text { Eva Guadarrama Brito apoyo }\end{array}$ \\
\hline Supervisión & Antonina Galván Fernández principal \\
\hline Administración de Proyectos & Antonina Galván Fernández principal \\
\hline Adquisición de fondos & Antonina Galván Fernández principal \\
\hline
\end{tabular}

